\title{
ESTUDO DO POSICIONAMENTO DE LÍNGUA E LÁBIOS EM SUJEITOS COM DISFUNÇÃO TEMPOROMANDIBULAR E DOR OROFACIAL
}

\section{Study of tongue and lip positions in patients with temporomandibular disorder and orofacial pain}

Vivian Ferreira Matos ${ }^{(1)}$, Florence Mitsue Sekito ${ }^{(2)}$

\begin{abstract}
RESUMO
Objetivo: verificar a posição de repouso de língua e lábios em sujeitos com Disfunção Temporomandibular (DTM) e analisar a intensidade da dor em músculos mastigatórios. Métodos: foram avaliados 44 sujeitos de ambos os sexos com média de idade de 42,52 anos. Foram realizadas três avaliações: exame clínico visual, averiguando a posição de repouso da língua, seguido de avaliação subjetiva e objetiva da dor pela Escala Visual Analógica (EVA) e palpação dos músculos mastigatórios. Resultados: 23 (52,27\%) posicionaram a língua no palato e 21 (47,73\%) na posição baixa. Dos sujeitos que posicionaram a língua no palato, 73,91\% deles referiram dor à palpação em masseter; $56,52 \%$ na região cervical; $43,48 \%$ em temporais; $39,13 \%$ em digástricos e $52,17 \%$ em região articular. Encontraram-se relações estatisticamente significantes entre queixa subjetiva e objetiva da dor relativo aos músculos cervicais $(p=0,026)$, temporais $(p=0,019)$, digástricos $(p=0,005)$ e região articular $(p=0,013)$. Na amostra foram encontrados $88,63 \%$ de componente miálgico e $56,81 \%$ artrálgico. Conclusão: a posição não elevada da língua não se confirmou em pacientes com DTM, uma vez que a distribuição foi equitativa, com ausência de correlação entre dor e posição de língua, predomínio de lábios fechados e dores miálgicas mais freqüentes que as artrálgicas.
\end{abstract}

DESCRITORES: Língua; Dor Facial; Síndrome da Disfunção da Articulação Temporomandibular

\section{INTRODUÇÃO}

As dores de origem muscular, da Articulação Temporomandibular (ATM) e da dentição são queixas coletivamente conhecidas como Disfunção Temporomandibular (DTM) ${ }^{1}$, que são sinais e sintomas advindos de trauma, inflamação e/ou infecção que levam a alterações músculo-esqueletais prejudicando o sistema estomatognático ${ }^{2}$.

Recentemente, com a interação de profissionais atuando na área da DTM, a posição habitual de repouso da língua $(\mathrm{PHL})$ adquire atenção especial,

(1) Fonoaudióloga; Clínica Odontológica: CERTO Odontologia, Rio de Janeiro, RJ; Especialização em Motricidade Orofacial pelo CEFAC - Pós-Graduação em Saúde e Educação.

(2) Dentista; Universidade Estadual do Rio de Janeiro, UERJ, Rio de Janeiro, RJ; Mestre em Odontologia pela Universidade Federal do Rio de Janeiro.

Conflito de interesses: inexistente uma vez que as dores de origem muscular e músculo-esqueletal são as mais prevalentes. Nestes casos, a hiperatividade muscular é uma das grandes causadoras e perpetuadoras desta condição patológica, reforçando a necessidade de diminuir ou eliminar quaisquer fatores que possam incrementar o aumento da função do músculo ${ }^{3}$.

Para a Fonoaudiologia, é apontado que a referência da $\mathrm{PHL}$ refere-se a manutenção da ponta contra a papila palatina, atrás dos incisivos centrais ${ }^{4,5}$. Este conceito foi sustentado por décadas, porém hoje com novas pesquisas ${ }^{6-8}$, observase que esta definição vem sendo contestada.

Autores ${ }^{9-11}$ alertaram a importância da posição de repouso da língua afirmando que esta, junto da posição de repouso dos lábios, influenciou muito mais na forma da arcada dentária ${ }^{9,10}$ do que a pressão exercida pela língua durante a fala e a deglutição ${ }^{10,11}$. 
Um estudo utilizando sensores intra-orais (para avaliação da $\mathrm{PHL}$ ) posicionados nos incisivos e molares superiores e inferiores mostraram uma pressão lingual significativamente maior na região do molar inferior ${ }^{6}$.

Outro trabalho avaliando exames cefalométricos demonstrou opinião controversa, pois verificou a predominância da posição baixa durante o repouso e a deglutição ${ }^{7}$, enquanto outro estudo observou em $61 \%$ da amostra a língua em contato com incisivos superiores e inferiores. Já em $25,2 \%$ dos casos, ela esteve em contato somente com incisivos inferiores e nenhum contato na região superior da arcada ${ }^{12}$.

Pesquisa fonoaudiológica ${ }^{8}$ utilizando fina camada de Sulfato de Bário sobre a língua, para depois radiografá-la, também revelou predominância na posição de língua com ápice rebaixado.

Em 1983, o programa 6X6 de tratamento para a disfunção biomecânica do sistema craniocervical e craniomandibular recomendou que o terço anterior da língua deveria ser mantido contra o palato fazendo leve pressão durante o repouso. $\mathrm{O}$ autor afirmou que este era um dos fatores mais importantes para o equilíbrio ortoestático do corpo ${ }^{13}$, sendo esta a posição referenciada por fonoaudiólogos 4,5 .

Todavia, este parâmetro tem recebido críticas, instigando os estudos nesta área, uma vez que estudos eletromiográficos (EMG) ${ }^{3,6}$ revelaram aumento na atividade elétrica de determinados músculos mastigatórios quando a língua foi mantida elevada no palato duro.

O objetivo da pesquisa foi verificar a posição habitual de repouso da língua e dos lábios em sujeitos com DTM, para depois relacionar esta posição à sensação subjetiva de dor e à avaliação álgica objetiva nos grupos musculares mastigatórios.

\section{MÉTODOS}

Participaram desse estudo 44 sujeitos pertencentes ao serviço de triagem da Clínica de Oclusão, DTM e Dor Orofacial da Faculdade de Odontologia da Universidade Estadual do Rio de Janeiro (UERJ), em que $36(81,81 \%)$ eram mulheres e 8 $(18,18 \%)$ homens adultos, com idade média de 42,52 anos (faixa etária entre 21 e 71 anos).

Os sujeitos foram incluídos nesta amostra pela apresentação consecutiva à clínica supracitada, apresentando queixa de Dor Orofacial ou na região das ATMs de intensidades leve a grave, de forma aguda ou crônica. Foram excluídos do estudo sujeitos sindrômicos, com alterações sistêmicas e neurológicas, e grupo controle.

A verificação foi feita pela fonoaudióloga, com uso de protocolo de anamnese em paciente com DTM e controle, colhido dados de componentes miálgicos e artrálgicos, hábitos orais deletérios, e avaliação da posição habitual de repouso da língua $(\mathrm{PHL})$, sensação de dor através da Escala Visual Analógica (EVA) e palpação muscular, para posterior relação subjetiva da dor.

O método de avaliação foi delineado para esse estudo, porém, baseado em pesquisas de PHL com utilização de Sulfato de Bário ${ }^{8}$ e corante comestível ${ }^{14}$. Foi utilizado nos pacientes com DTM e grupo controle creme dental infantil da marca Tandy, sabor Tutti-fruti, de coloração azul. Foi aplicado ao ápice da língua, pequena quantidade de pasta e o sujeito foi orientado a permanecer em repouso, de boca fechada, por 10 segundos cronometrados. Avaliouse a região oral (superior ou inferior) que recebeu o contato da pasta. A análise foi confirmada pedindo ao sujeito para observar sua posição de repouso da língua, de olhos fechados, baseando-se na sua propriocepção. A posição foi classificada em elevada, quando houve contato da pasta com a papila palatina e não elevada, quando a pasta marcou os incisivos superiores (língua interposta) ou abaixo deles (língua baixa). Para registrar a sensação de dor foi utilizada a Escala EVA ${ }^{15,16}$ através de uma linha não milimetrada, de $100 \mathrm{~mm}$ de extensão. O sujeito foi orientado apenas a marcar sua sensação dolorosa (após explicação de que a linha se referia ao que ele sentia em relação a dor) começando em $0 \mathrm{~mm}$, ou seja, ausência de dor, e terminando em $100 \mathrm{~mm}$, a sensação máxima). Mensurou-se esta marcação com régua milimetrada, de 0 ao local marcado, quantificando a sensibilidade dolorosa de cada um. Esta sensação dolorosa foi considerada de nível: leve a moderado (0 a $69 \mathrm{~mm}=\mathrm{EVA}<7$ ) ou intenso (70 a $100 \mathrm{~mm}=\mathrm{EVA}>7$ ).

A palpação foi feita de forma mais objetiva, nos feixes musculares ligados a ATM e mastigação. Cada feixe foi numerado de acordo com o nível álgico, onde o sujeito ao ser palpado, referia ausência ou presença de dor e sua intensidade no momento da palpação. Utilizou-se a classificação: 0 para nenhuma dor, 1 sensibilidade ou incômodo, 2 dor, 3 dor com retração facial e T para dor irradiada (trigger-point). Para a pontuação 0 e 1 foi considerado sem dor muscular e para os que tiveram 2, 3 ou $\mathrm{T}$, foram considerados com dor muscular.

A análise estatística procurou investigar as regiões de ocorrência de dor à palpação, relacionou queixas subjetivas e objetivas da dor, relativas aos músculos investigados em região articular, e a $\mathrm{PHL}$ foi relacionada à sensação dolorosa dos grupos musculares e articular.

O presente projeto de pesquisa foi aprovado e considerado sem risco pelo Comitê de Ética em Pesquisa do CEFAC - Pós-Graduação em Saúde e Educação, sob número 071/04. Os sujeitos foram 
concordantes quanto à avaliação feita e os métodos utilizados para tal, recebendo informações detalhadas sobre a pesquisa antes do consentimento.

Os dados foram obtidos por meio da análise estatística pelos testes de qui-quadrado $\left(x^{2}\right)$ ou teste exato de Fisher para comparação de dados qualitativos. O critério de determinação de significância adotado foi o nível de $5 \%$, ou seja, quando o valor de $p$ do teste estatístico foi menor ou igual a 0,05 , considerou-se significância estatística.

\section{RESULTADOS}

Foram encontrados $88,63 \%$ (39 sujeitos) de componente miálgico e $56,81 \%(n=25)$ artrálgico. A anamnese revelou que muitos sujeitos se queixaram de dor em mais de uma região: $27,27 \%$ nas ATMs $(n=12), 13,64 \%$ na nuca $(n=6), 67,83 \%$ no ouvido ( $n=14), 38,64 \%$ na face $(n=17), 29,55 \%$ no pescoço $(n=13)$ e $13,64 \%$ nos dentes $(n=6)$.

Dentre as características da queixa, verificouse que $63,64 \%$ indivíduos $(n=28)$ ocorreram de forma bilateral variando de dor constante a intermitente, de intensidade forte em $53,49 \%$ dos sujeitos $(n=23)$, e na grande maioria de forma crônica em $78,57 \%(n=32)$. Houve a confirmação do hábito de pelo menos uma parafunção em $68,18 \%$ indivíduos $(n=30)$. A presença de dor a mastigação foi ressaltada em $55,81 \%(n=24)$.
A posição da língua mostrou-se elevada em $52,27 \%$ sujeitos $(n=23)$ da amostra total e em $47,73 \% \quad(n=21)$ na posição menos elevada (Figura 1). A relação entre posição da língua e EVA não foi estatisticamente significante $(p=0,22)$. Quanto à avaliação da posição dos lábios a predominância foi da posição fechada em $97,73 \%$ dos sujeitos $(n=43)$.

A análise estatística, relacionando a queixa subjetiva da dor (anamnese) e a presença de dor obtida no exame de palpação, determinou relações estatisticamente significantes em:

A relação entre EVA e dor nos músculos Temporais, revelou que pacientes com EVA intenso (EVA > 7) apresentaram proporção de dor nestes músculos significantemente maiores $(p=0,019)$ que nos pacientes com EVA menos intenso; como mostra a Figura 1.

Os pacientes com EVA intenso apresentaram proporção de dor nos músculos supra-hióideos significantemente maior $(p=0,005)$, que nos pacientes com EVA menos intenso; conforme a Figura 2.

Os pacientes com EVA intenso apresentaram proporção de dor significantemente maior nos músculos cervicais, que nos pacientes com EVA menos intenso $(p=0,026)$; como ilustra a Figura 3.

Os pacientes com EVA intenso apresentaram dor à palpação em região articular significantemente maior, que nos pacientes com EVA menos intenso $(p=0,013)$, como mostra a Figura 4.

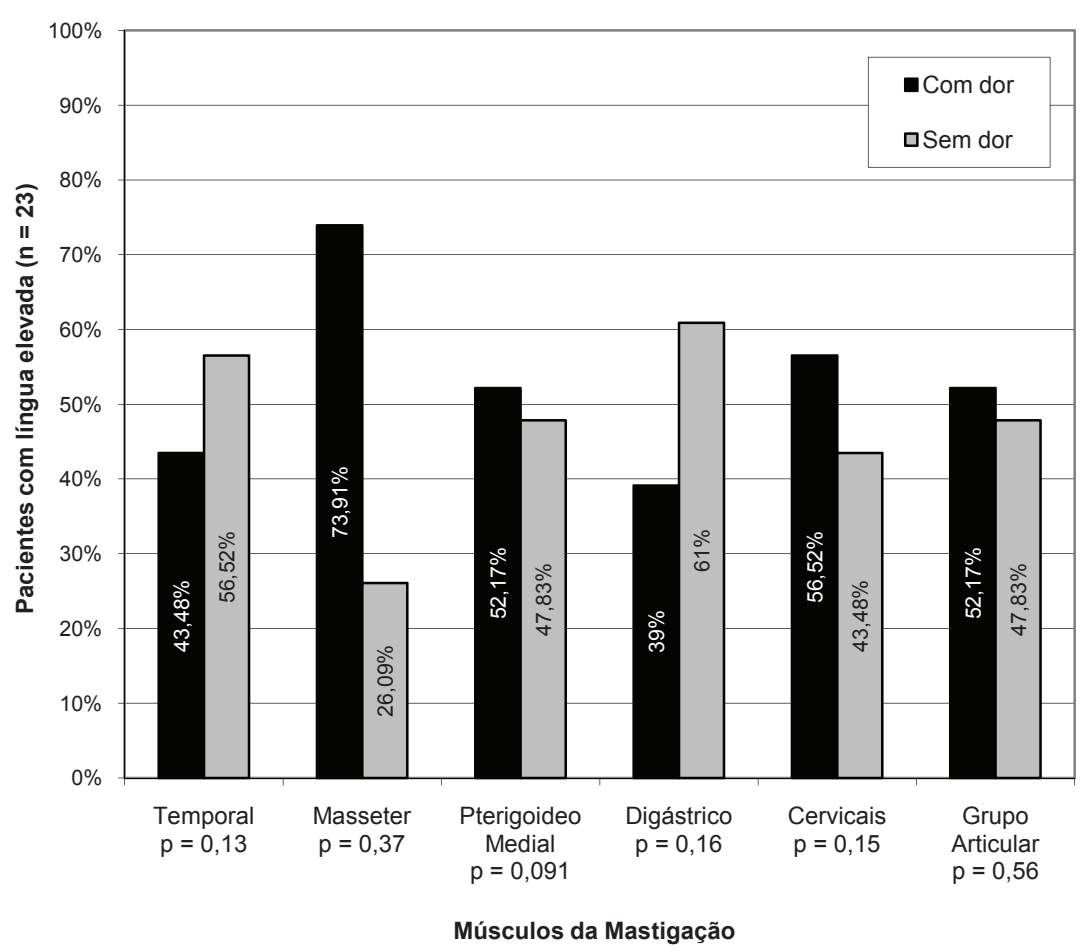

Teste utilizado: Qui-quadrado $\left(\mathrm{x}^{2}\right)$ ou Teste Exato de Fisher

Figura 1 - Relação da posição elevada de língua com Grupo Muscular e Articular 


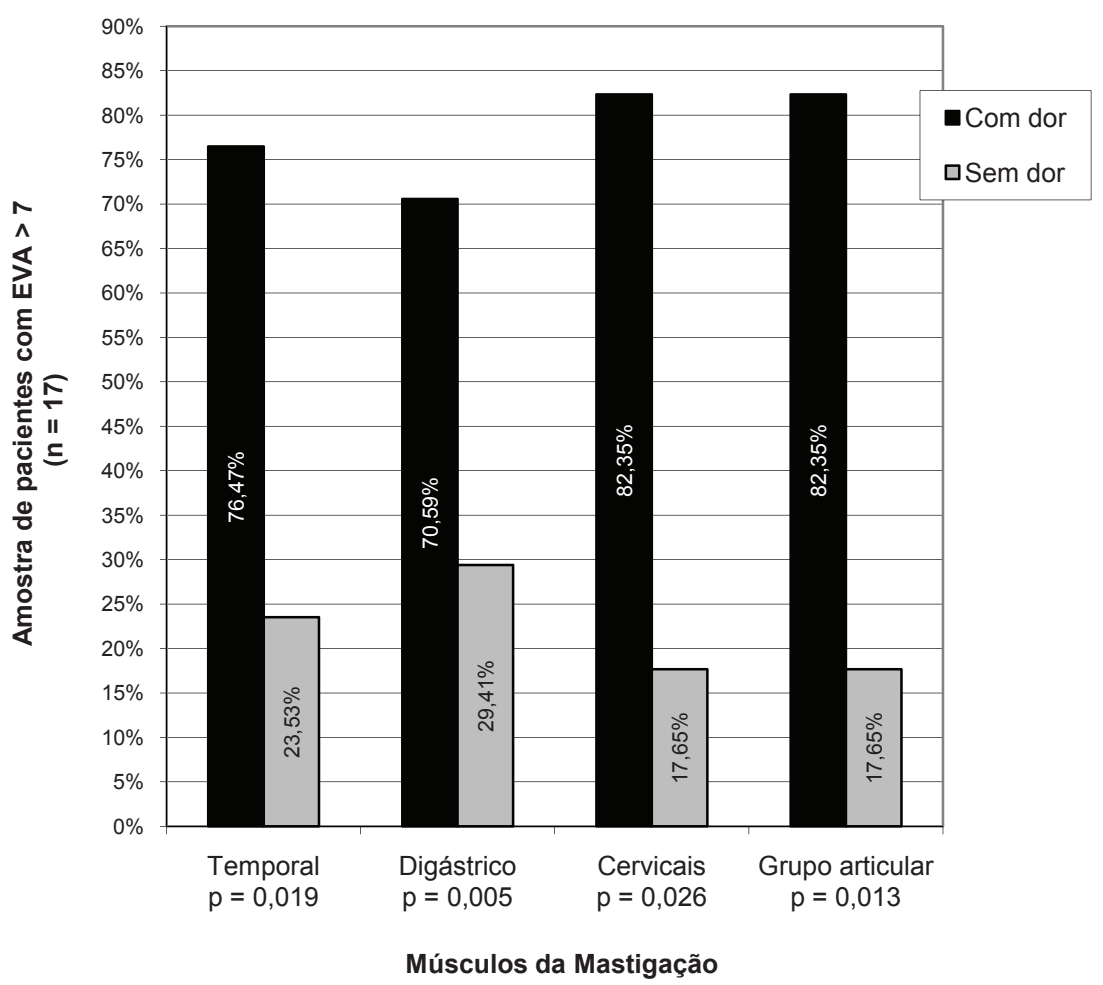

Teste utilizado: Qui-quadrado $\left(\mathrm{x}^{2}\right)$ ou Teste Exato de Fisher

Figura 2 - Relação significativa de sujeitos com EVA > 7 e Grupo Muscular e Articular

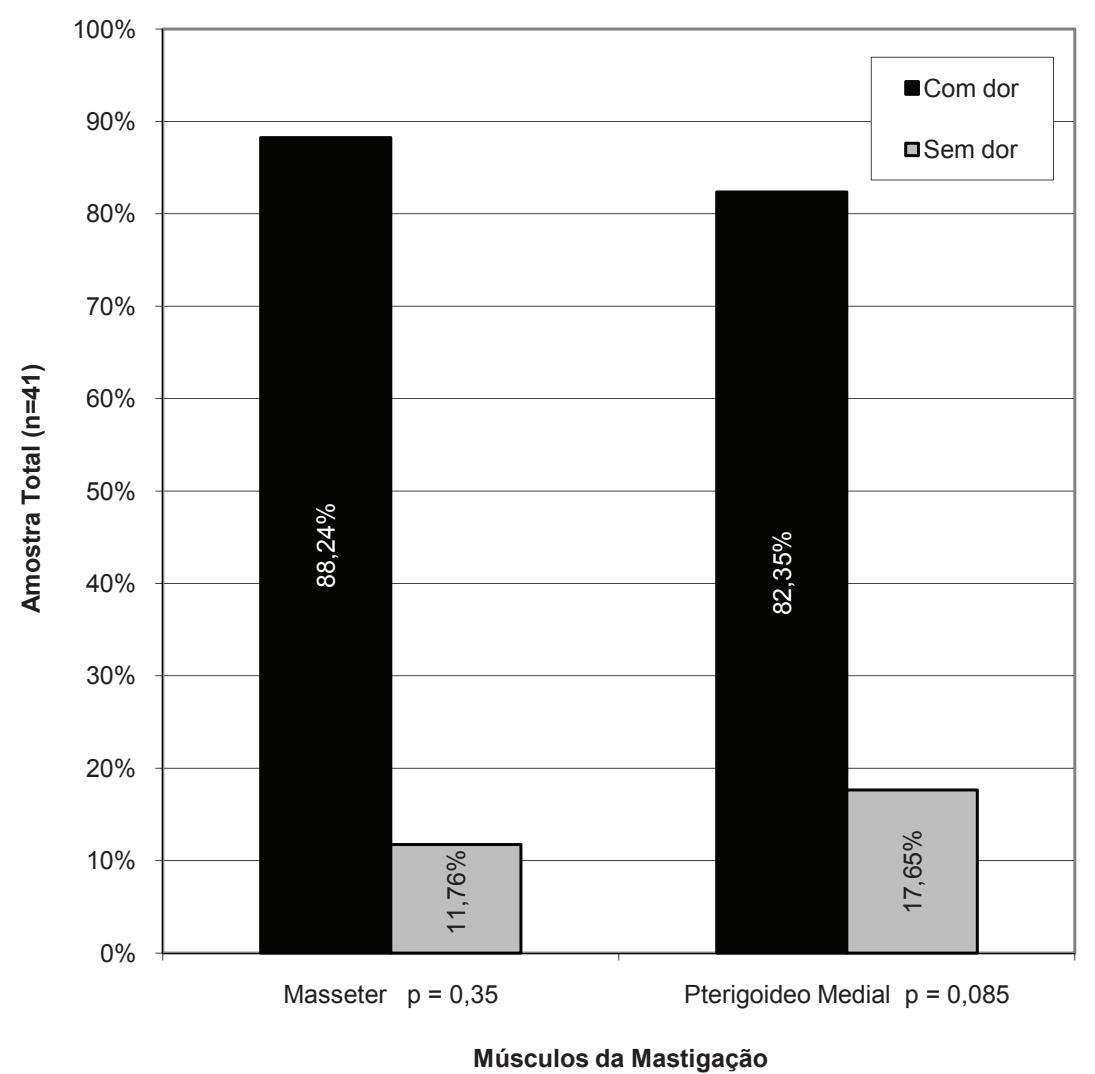

Teste utilizado: Qui-quadrado $\left(\mathrm{x}^{2}\right)$ ou Teste Exato de Fisher

Figura 3 - Relação não significativa de sujeitos com EVA > 7 e Grupo Muscular 


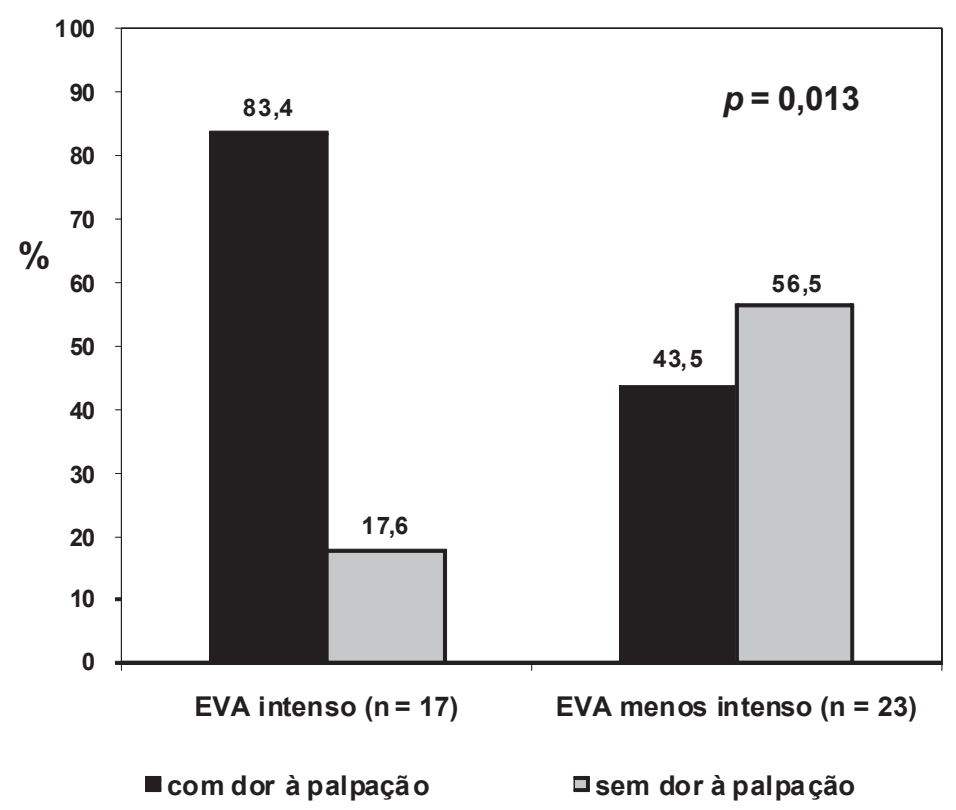

Teste utilizado: Qui-quadrado $\left(\mathrm{x}^{2}\right)$ ou Teste Exato de Fisher

Figura 4 - Relação significante entre EVA e Dor em Região Articular

Não foi encontrada relação significante entre EVA e os músculos Masseteres ( $p=0,35)$. Pode-se dizer que existe uma tendência discreta entre presença de dor nos músculos Pterigóideos Mediais e intensidade de EVA $(p=0,085)$.

\section{DISCUSSÃO}

A importância da posição habitual da língua tem sido reconhecida como fundamental no tratamento fonoaudiologico e nas modalidades de ortodontia preventiva, interceptiva e corretiva.

Todavia, a determinação da posição espacial específica do ápice da língua durante a posição habitual de repouso revelou que existem poucos relatos elucidando esta questão, até onde se alcançou na literatura cientifica. A PHL em repouso e com lábios vedados é difícil de ser obtida devido a dificuldade de visualização direta do ápice da língua ${ }^{8}$.

Uma das técnicas conhecidas para estudo sobre $\mathrm{PHL}$ foi com o uso de imagens de teleradiografia lateral fazendo aplicação de contraste de Sulfato de Bário na superfície da língua para melhor visibilidade ${ }^{8}$. Para a avaliação clínica da posição de repouso, foi utilizado corante comestível nas bordas linguais do sujeito a fim de verificar o ponto de apoio da língua durante a deglutição ${ }^{16}$. Para esse estudo, a metodologia das técnicas supra citadas foi variada, uma vez que, corriqueiramente na clí- nica fonoaudiológica, é utilizada pela facilidade e rapidez de aquisição da $\mathrm{PHL}$, a baixo custo e sem o uso de irradiação ionizante.

Estudos de anatomofisiologia ressaltaram que a língua seria um órgão de importância fundamental dentro do sistema estomatognático, por possibilitar a fonação, deglutição, sucção, mastigação, como também o relevante papel na postura cranio-orocervical. Estes estudos relataram que o mecanismo de funcionamento da língua seria realizado através dos grupos musculares da musculatura intrínseca e extrínseca da língua, na qual a musculatura extrínseca faria o papel de apoio na base, permitindo que a musculatura intrínseca realize suas movimentações e deslocamentos ${ }^{17,18}$.

Este raciocínio levaria a supor que os movimentos do ápice da língua, principalmente os de afilamento e projeção seriam de responsabilidade da musculatura intrínseca, ocorrendo a partir de uma posição-base inicial fornecida pela musculatura extrínseca ${ }^{17,18}$. Assim, poder-se-ia pressupor que a posição de apoio do ápice da língua contra a papila palatina não poderia ser considerada como uma posição de repouso, já que implicaria em sair da posição inicial. A posição de apoio no ápice estaria ligada a um movimento inicial de projeção lingual em direção contrária à da origem do músculo, por meio de contrações sincrônicas da musculatura intrínseca auxiliada pela extrínseca. A hipótese acima levantada foi reinterada em estudo 
científico, concordando que a posição elevada da língua não pode ser considerada como "repouso" uma vez que, para manter a língua contra a força da gravidade, faz-se muito esforço, e com isso há um dispêndio de energia, gerando fadiga ${ }^{6}$.

As opiniões sobre a intensidade de atividade muscular nas posições de repouso mandibular, língua e lábios mostraram divergências na literatura, pois alguns autores publicaram que os músculos deveriam estar ativos e outros acharam evidências de mínima atividade ou inatividade muscular 19-22.

Em 1981, um estudo ${ }^{23}$ sobre posição de repouso mandibular citou a definição do dicionário de Termos Odontológicos quanto à relação postural da mandíbula com a maxila em repouso, como: quando os côndilos estivessem numa posição neutra na cavidade condilar. Eles observaram que a atividade muscular diminuiu conforme a abertura vertical de boca, sendo esta diminuição, decorrente da redução da atividade dos músculos levantadores da mandíbula, responsáveis pelo fechamento mandibular. Seus resultados sugeriram que a posição vertical de repouso da mandíbula é um ponto específico no espaço onde os músculos mandibulares estavam em máximo relaxamento, e que esta posição pôde ser identificada através da eletromiografia pela atividade muscular mínima ou ausente.

O uso da EMG ${ }^{3,6}$ permitiu análise do comportamento da atividade elétrica durante o processo de elevação da língua. Viu-se que este processo gerou um aumento na atividade elétrica dos músculos mastigatórios: masseter, temporal, supra-hióideo e digástrico ventre anterior. Assim, verificou-se que a posição elevada poderia contribuir para o aumento da dor e desconforto muscular, principalmente em sujeitos com dores de origem músculo-esqueletal como as DTMs e Dores Orofaciais ${ }^{3}$. Estes achados corroboram a hipótese de que terapias que incentivam o posicionamento da língua contra a papila palatina durante o repouso possa igualmente agravar ou perpetuar disfunções mastigatórias e articulares. No presente estudo não se pôde determinar a prevalência das posições elevada e não elevada em sujeitos com DTM. Contudo, foi possível correlacionar significantemente a presença de dor em alguns dos músculos supracitados, como os temporais, digástricos e pterigóideos mediais (sinérgicos aos masseteres), achados semelhantes aos encontrados nos estudos desses autores ${ }^{3,6}$.

Estudos transversais e longitudinais observaram que sinais e sintomas da DTM aumentaram em frequência e gravidade, na segunda e terceira décadas de vida, entretanto nessa amostra encontrou-se uma idade média de 42,52 anos. Quanto à avaliação de sintomas relacionados a ruídos na ATM, dor na ATM e dor muscular, esses achados concordam com a literatura, ocorrendo em maior número em mulheres do que em homens, na proporção mulheres-homens de 4,5:1 ${ }^{1}$.

Averiguou-se que as queixas mais frequentes dos pacientes com DTM são semelhantes às encontradas na literatura ${ }^{1,2}$, como: dor nas ATMs, no ouvido, na face e na cabeça, confirmando sua associação com a ocorrência de pelo ao menos um tipo de parafunção $(68,18 \%)$.

Os ruídos articulares são relatados variando de 8 a $37 \%$ de prevalência na população ${ }^{24}$ e até $17,5 \%$ em sujeitos com DTM ${ }^{1}$. Nessa amostra encontrouse alta prevalência de queixas de ruídos intra-articulares $(96,55 \%)$ diferente dos autores supracitados, de forma unilateral.

O vedamento labial encontrado na maioria dos sujeitos parece reiterar opiniões que relacionam pacientes com DTM à presença de tensão em região frontal, bucinadores e orbicular dos lábios ${ }^{25}$.

Esse estudo não mostrou prevalência estatisticamente significante da predominância da posição elevada da língua, mostrando uma equivalência na frequência entre posição elevada e não elevada.

Os resultados encontrados não puderam determinar uma relação significante entre a posição elevada da língua e maior intensidade de dor (EVA). Entretanto, verificou-se a presença de dor intensa em vários músculos e em região articular, mesmo em sujeitos com língua elevada, quando seria esperado que esses fossem menos sintomáticos. Outras importantes relações foram verificadas, entre dor intensa e dor nos músculos temporais, e Digástricos e Cervicais dos sujeitos dessa amostra. Esses resultados parecem indicar que a língua poderia atuar de forma indireta sobre esses músculos, devido ao seu papel no sistema de cadeia muscular crânio-oro-cervical ${ }^{17,18}$.

A abordagem terapêutica, fonoaudiológica e odontológica, aos pacientes com DTM procura minimizar os sintomas álgicos adequando a atividade muscular e o sinergismo entre as componentes do sistema mastigatório. Para tal, uma das referências utilizadas é a posição de repouso da língua e da mandíbula, posição esta que proporcionaria menor tônus e atividade muscular, minimizando os efeitos de hiperfunção e fadiga, além de reduzir a pressão intra-articular e instabilidade ortopédica crânio-mandibular.

Os achados deste estudo vão de encontro à opinião de outros ${ }^{3,8,25,26}$, de que a PHL no repouso fisiológico não ocorre com a ponta da língua mantida contra a papila palatina atrás dos incisivos centrais. Eles encontraram dados distintos em suas pesquisas que discordam do conceito sustentado por décadas ${ }^{4,5,13}$. 


\section{CONCLUSÃO}

Diante das análises do estudo pode-se considerar, no grupo de pacientes com DTM, que a posição fechada de lábios foi predominante. Todavia no que concerne à posição da língua, houve distribuição equitativa entre PHL elevada e não elevada; e não houve relação entre sensação dolorosa (EVA) e posição elevada da língua. Na palpação, as dores miálgicas foram mais frequentes que as artrálgicas.

\section{ABSTRACT}

Purpose: to check the habitual tongue and lips rest position in subjects with Temporomandibular Dysfunction (TMD), and to analyze their pain complaint in masticatory muscles. Methods: 44 subjects, of both genders and mean age of 42.52 years were evaluated. Three evaluations were carried out: visual clinical examination as for tongue habitual rest position, pain complains using visual analogical scale (VAS) and bilateral masticatory muscle palpation assessing pain intensity. Results: 23 subjects $(52.27 \%)$ showed the tongue at the palatine papilla and $21(47.73 \%)$ showed in different position than the elevated. The subjects who showed the tongue against the palatine papilla, referred pain during the palpation of Masseters (73.91\%), Cervical muscles (56.52\%), Temporals (43.48\%), Digastrics muscles $(39.13 \%)$ and in the Temporomandibular Joint (TMJ) region $(52.17 \%)$. Statistically significant correlations were found among pain complains (VAS) and palpation pain intensity concerning: Cervical Muscles $(p=0.026)$, Temporals $(p=0.019)$, Digastrics $(p=0.005)$ and TMJ region $(p=0.013)$. The sample demonstrated components comprising $88,63 \%$ of masticatory muscle pain and $56.81 \%$ complained pain in the Temporomandibular Joint region. Conclusion: the non-elevated position of the tongue was not confirmed in TMD subjects, with no correlation between pain and tongue rest position. We observed closed lips rest position and predominance of mialgic pain instead of arthralgic pain.

KEYWORDS: Tong; Facial Pain; Temporomandibular Joint Dysfunction Syndrome

\section{REFERÊNCIAS}

1. Okeson JP. Dores bucofaciais de Bell. 5. ed. São Paulo: Quintessence; 1998.

2. Okeson JP. Fundamentos de oclusão: desordens temporomandibulares. 2. ed. São Paulo: Artes Médicas; 1992.

3. Carlson CR, Sherman JJ, Studts JL, Bertrand $\mathrm{PM}$. The effects of tongue position on mandibular muscle activity. J Orofac Pain 1997; 11(4):291-7.

4. González NZT, Lopes LD. Fonoaudiologia e ortopedia maxilar na reabilitação orofacial: tratamento precoce e preventivo, terapia miofuncional. São Paulo: Santos; 2000.

5. Felício CM. Fonoaudiologia aplicada a casos odontológicos: motricidade oral e audiologia. São Paulo: Pancast; 1999. 102 p.

6. Frohlich K, Thuer U, Ingervall B. Pressure from the tongue on the teeth in young adults. Angle Orthod. 1991; 61(1):17-24.

7. Fishman LS. Postural and dimensional changes in the tongue from rest position to occlusion. Angle Orthod. 1969; 39(2):109-13.
8. Tessitore A, Crespo AN. Analise radiográfica da posição habitual de repouso da língua. Pró-Fono. 2002; 14(1):7-16.

9. Proffit WR. Muscle pressures and tooth position: North American whites and Australian aborigines. Angle Orthod. 1975; 45(1):1-11.

10. Proffit WR, McGlone RE, Barrett MJ. Lip and tongue pressures related to dental arch and oral cavity size in Australian aborigines. J Dent Res. 1975; 54(6):1161-72.

11. Mc Glone RE, Proffit WR. Correlation between functional lingual pressure and oral cavity size. Cleft Palate J. 1972; 9(3):229-35.

12. Peat $\mathrm{JH}$. A cephalometric study of tongue position. Am J Orthod. 1968; 54(5):339-51.

13. Rocabado $M$. Arthrokinematics of the temporomandibular joint. Dental Clin North Am. 1983; 27(3):573-94.

14. Rugh JD, Drago CJ. Vertical dimension: a study of clinical rest position and jaw muscle activity. J Prosthet Dent. 1981; 45(6):670-5.

15. Campos M, Morais PL, Pupo AS. Effect of cyproterone acetate on alpha 1 -adrenoceptor subtypes in rat vas deferens. Braz $\mathrm{J}$ Med Biol Res. 2003 nov; 36(11):1571-81. 
16. Corrêa LL, Platt MW, Carraro L, Moreira RO, Faria Júnior R, Godoy-Matos AF, et al. Avaliação do efeito da sibutramina sobre a saciedade por escala visual analógica em adolescentes obesos. Arq Bras Endocrinol Metab. 2005 abr; 49(2):286-90.

17. Yemm R, Berry DC. Passive control in mandibular rest position. J Prosthet Dent. 1969; 22(1):30-6.

18. Hickey JC, Williams BH, Woelfel JB. Stability of mandibular rest position. J Prosthet Dent. 1961; 11(3):566-72.

19. Pruzansky S. The control of the posture of the mandible during rotation of the head. J Dent Res Abstr. 1955; 129.

20. Feldman S, Leupold RJ, Staling LM. Rest vertical dimension determined by electromyography with biofeedback as compared to conventional methods. J Prosthet Dent. 1978 aug; 40(2):216-9.

21. Vitti M, Basmajian J. Muscles of mastication in small children: an electromyographic analysis. Am J Orthod. 1975; 68(4):412-9.
22. Garreto AL. Experiência fonoaudiológica no atendimento odontopediátrico e ortodôntico. In: Marchesan IQ. Tratamento da deglutição: a atuação do fonoaudiólogo em diferentes países. São José dos Campos: Pulso; 2005. p. 35-59.

23. Lowe AA, Takada K, Yamagata Y, Sakuda M. Dentoskeletal and tongue soft-tissue correlates: a cephalometric analysis of rest position. Am J Orthod. 1985; 88(4):333-41.

24. Williamson EH, Hall JT, Zwemer JD. Swallowing patterns in human subjects with and without temporomandibular dysfunction. Am $\mathrm{J}$ Orthod Dentofac Orthop. 1990; 98(6):507-11.

25. Kydd WL, Akamine JS, Mendel RA, Kraus BS. Tongue and lip forces exerted during deglutition in subjects with and without an anterior open bite. $J$ Dent Res. 1963; 42(3):858-66.

26. Mory M, Baroni L, Tessitore A, Assencio-Ferreira V. Análise radiográfica da posição habitual da língua nos portadores de distoclusão. Rev CEFAC. 2003; 5(6):231-4.

RECEBIDO EM: 05/11/2007

ACEITO EM: 22/04/2009

Endereço para correspondência:

Vivian Ferreira Matos

Rua Heleno de Freitas, 70 Casa 102

Rio de Janeiro - RJ

CEP: 21920-385

E-mail: vivian1601@ hotmail.com

vivian1601@gmail.com 